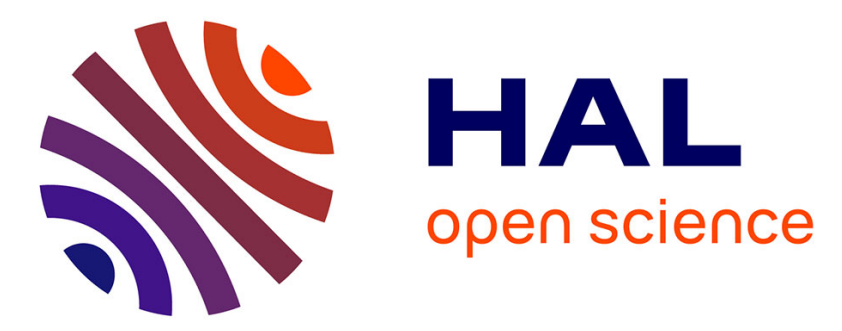

\title{
Time-dependent contribution of non neuronal cells to BDNF production after ischemic stroke in rats.
}

Yannick Béjot, Anne Tessier, Claire Cachia, Maurice Giroud, Claude Mossiat, Nathalie Bertrand, Philippe Garnier, Christine Marie

\section{- To cite this version:}

Yannick Béjot, Anne Tessier, Claire Cachia, Maurice Giroud, Claude Mossiat, et al.. Time-dependent contribution of non neuronal cells to BDNF production after ischemic stroke in rats.. Neurochemistry International, 2011, 58 (1), pp.102-11. 10.1016/j.neuint.2010.10.019 . hal-00701314

\section{HAL Id: hal-00701314 https://u-bourgogne.hal.science/hal-00701314}

Submitted on 25 May 2012

HAL is a multi-disciplinary open access archive for the deposit and dissemination of scientific research documents, whether they are published or not. The documents may come from teaching and research institutions in France or abroad, or from public or private research centers.
L'archive ouverte pluridisciplinaire HAL, est destinée au dépôt et à la diffusion de documents scientifiques de niveau recherche, publiés ou non, émanant des établissements d'enseignement et de recherche français ou étrangers, des laboratoires publics ou privés. 
Title : Time-dependent contribution of non neuronal cells to BDNF production after ischemic stroke in rats.

Yannick Béjot ${ }^{a, b, c, d}$, Anne Tessier ${ }^{a, b}$, Claire Cachia ${ }^{b}$, Maurice Giroud ${ }^{b, c, d}$, Claude Mossiat ${ }^{a, b}$, Nathalie Bertrand ${ }^{\mathrm{a}, \mathrm{b}}$, Philippe Garnier ${ }^{\mathrm{a}, \mathrm{b}}$, Christine Marie ${ }^{\mathrm{a}, \mathrm{b},{ }^{*}}$

a Laboratoire INSERM U887 Motricité-Plasticité, Dijon F-21078 France.

${ }^{\mathrm{b}}$ Université de Bourgogne, Dijon F-21079 France

${ }^{\mathrm{c} D e p a r t m e n t}$ of Neurology, University Hospital, Dijon F-21000 France

${ }^{d}$ Centre d'Epidémiologie des Populations, EA4184, Dijon F-21000 France

${ }^{*}$ Corresponding author at: Laboratoire INSERM U887 Motricité-Plasticité, Faculté de Pharmacie, 7 Boulevard Jeanne d'Arc, BP 87900, 21079 Dijon, France. Tel.: +33 3803932 25; fax: +33380393227

E-Mail address: chmarie@u-bourgogne.fr (Pr. C. Marie). 


\section{ABSTRACT}

Although brain-derived neurotrophic factor (BDNF) plays a central role in recovery after cerebral ischemia, little is known about cells involved in BDNF production after stroke. The present study testes the hypothesis that neurons are not the unique source of neosynthesized BDNF after stroke and that non neuronal-BDNF producing cells differ according to the delay after stroke induction. For this purpose, cellular localization of BDNF and BDNF content of each hemisphere were analysed in parallel before and after $(4 \mathrm{~h}, 24 \mathrm{~h}$ and $8 d$ ) ischemic stroke in rats. Stroke of different severities was induced by embolization of the brain with variable number of calibrated microspheres allowing us to explore the association between BDNF production and neuronal death severity. The main results are that a) unilateral stroke increased BDNF production in both hemispheres with a more intense and long-lasting effect in the lesioned hemisphere, b) BDNF levels either of the lesioned or unlesioned hemispheres were not inversely correlated to neuronal death severity whatever the delay after stroke onset, c) in the unlesioned hemisphere, stroke resulted in increased BDNF staining in neurons and ependymal cells (at $4 \mathrm{~h}$ and $24 \mathrm{~h}$ ), d) in the lesioned hemisphere, beside neurons and ependymal cells, microglial cells (at 24h), endothelial cells of cerebral arterioles (at $4 \mathrm{~h}$ and $24 \mathrm{~h}$ ) and astrocytes (at $8 \mathrm{~d}$ ) exhibited a robust BDNF staining as well. Taken together, overall data suggest that non neuronal cells are able to produce substantial amount of BDNF after ischemic stroke and that more attention should be given to these cells in the design of strategies aimed at improving stroke recovery through BDNFrelated mechanisms.

Keywords: BDNF localization, BDNF production, stroke, brain ischemia, rats 


\section{Introduction}

The brain derived neurotrophic factor (BDNF), a member of neurotrophin family protein, exerts strong survival and differentiation function during the development of the nervous system (Cohen-Cory et al. 2010). However, BDNF is still present in mature brain where it is stored and released from neurons in a use-dependent fashion and has been implicated in long term potentiation, learning and memory formation (Greenberg et al., 2009; Nagappan and Lu, 2005). BDNF also represents a crucial signalling molecule in adaptative brain plasticity after stroke (Cowansage et al., 2010 ; Lipsky and Marini, 2007; Mattson, 2008). Interventions that improve recovery of function are most often associated with increased BDNF levels in perilesional areas (Chen et al., 2005b; Kim et al., 2005; Vaynman et al., 2004). Conversely, attenuating BDNF levels or its effects following cerebral ischemia reduces neuroplastic changes or recovery of function either spontaneous or induced by rehabilitation (Chen et al., 2005a; Madinier et al., 2009; Ploughman et al., 2009). From these data, pharmacological strategies aimed at increasing post-ischemic cerebral BDNF production appear to be a promising option in the treatment of stroke. A first step in the design of such approaches is the characterization of BDNF-producing-cells according to the delay after stroke onset.

Despite the central role of BDNF in recovery after stroke, the proper effect of stroke on cerebral BDNF production has been surprisingly poorly investigated. Available studies support increased BDNF production after stroke as suggested by increased BDNF levels in areas collected either at the lesion site or around the lesion for at least one week following stroke (Kokaia et al., 1998; Madinier et al., 2009; Sulejczak et al., 2007). Because increased levels of BDNF mRNA were observed in degenerating and surviving neurons in the acute post-stroke period (Comelli et al., 1992; Kokaia et al., 1995; Rickhag et al., 2007; Zhao et al., 2000), it has been generally accepted that neurons are the predominant source of neosynthesized BDNF in the ischemic brain. However, the contribution of non neuronal cells is suspected from in vitro studies that report the ability of microglial cells, cerebral endothelial cells and astrocytes to express and secrete BDNF when exposed to conditions mimicking 
ischemia (Bayas et al., 2002; Jean et al., 2008; Lai and Todd, 2008; Miklic et al., 2004; Saha et al., 2006). In vivo, data reported BDNF expression by non neuronal cells such as astrocytes (Sato et al., 2009; Uchida et al. 2010) or microglia (Batchelor et al., 1999; Madinier et al., 2009; Nagamoto-Combs et al., 2007) but, to the best of our knowledge, studies specifically designed to assess their exact contribution to BDNF production are lacking.

In this context, the objective of our study was to investigate the contribution of neuronal versus non neuronal cells in stroke-induced BDNF production with respect of the delay after stroke onset. For this purpose, identification of BDNF-reactive cerebral cells was coupled to the measurement of BDNF levels in the whole hemispheres before and after (4h, $24 \mathrm{~h}$ and $8 \mathrm{~d}$ ) ischemic stroke in rats. Stroke was performed by means of intracarotid injection of calibrated microspheres (Bralet et al., 1979), a model which allows the modulation of neuronal death severity by varying the amount of injected microspheres (Demougeot et al., 2001). Thus, using this specific model of ischemia, if neurons are the predominant cellular source of BDNF, BDNF content of the lesioned hemisphere, which include both infarcted and surrounding non infarcted areas, should be inversely correlated to the degree of embolization. A first set of experiments was designed to investigate the relationship between individual hemispheric BDNF levels and degree of embolization, and the impact of embolization on hemispheric BDNF production. In a second set of experiments, cellular BDNF localization was examined before and after embolization. Then, based on the simultaneous analysis of changes in cells expressing BDNF and hemispheric BDNF levels, the time-dependent contribution of non neuronal versus neuronal cells to stroke-induced BDNF production was deduced.

\section{Materials and Methods}

\subsection{Materials}

Acrylamide and bis-acrylamide, sodium dodecylsulfate (SDS) and tween-20 were obtained from Bio-Rad (Ivry sur Seine, France). The polyvinylidene difluoride (PVDF) membranes 
were purchased from GE Healthcare (Orsay, France). All other reagents were purchased from Sigma-Aldrich except where otherwise noted. The rabbit polyclonal antibody raised against BDNF (AB1779SP) and the mouse monoclonal antibody recognizing NeuN (MAB377) were purchased from Chemicon (Molsheim, France). The mouse monoclonal CD11b (OX-42) that recognizes type 3 complement receptors of activated macrophage/microglia (MCA 275R) and the mouse monoclonal antibody raised against GFAP (G3893) for astrocytes characterization were obtained respectively from AbD Serotec (Darmstadt, Germany) and Sigma (Saint Quentin-Fallavier, France). For secondary antibodies, the Alexa Fluor 488- and 568-conjugated anti-rabbit and -mouse antibodies were purchased from Molecular probes and the horseradish peroxidase-conjugated anti-mouse antibody was obtained from Jackson ImmunoResearch Laboratories.

\subsection{Animal care}

All the experimental procedures were carried out on adult male Wistar rats (290-350 g, Depré, Saint-Doulchard, France). Rats were housed five per cage at $21^{\circ} \mathrm{C}$ under an artificial 12-h light and 12-h dark period with light on at $7 \mathrm{AM}$, and were allowed ad libitum access to food and water. The protocol was conducted according to the French Department of Agriculture guidelines (licence 1308).

\subsection{Ischemic stroke model}

Brain infarction was induced by irreversible occlusion of multiple arterioles in the left hemisphere and definitive ligature of the left common carotid artery (Bralet et al., 1979). Arteriolar occlusion was achieved by the injection into the left common carotid of variable amounts (2000, 3000 and 4000) of $50 \mu \mathrm{m}$ calibrated microspheres (carbonized microspheres, 3M, Cergy-Pontoise, France). This model results in multiple infarcts disseminated in the entire embolized hemisphere, the extent of infarcted areas being dependent on the degree of embolization. Briefly, after chloral hydrate anaesthesia (400 $\mathrm{mg} / \mathrm{kg}$, i.p.), $0.2 \mathrm{ml}$ of a suspension of microspheres $20 \%$ polyvinylpyrrolidone (PVP) was 
collected in a syringe containing $0.1 \mathrm{ml}$ of $20 \%$ PVP. Microspheres were then injected $(0.3 \mathrm{ml}$ for 25-30s) into the left common carotid artery after ligature of the external carotid artery in order to prevent embolization of extracerebral tissues. Then, the left internal carotid artery was definitively occluded. As a strong correlation was reported between the degree of embolization and the hemispheric content in the neuronal marker $\mathrm{N}$-acetyl-aspartate (Demougeot et al., 2001), neuronal death severity can be easily assessed from the determination of the degree of embolization. Intact rats were used as control animals.

\subsection{BDNF level measurement}

After chloral hydrate-anaesthesia and transcardial perfusion with saline in order to flush out blood from cerebral vasculature, the brain was removed, and the cerebellum, the hypothalamus and the mesencephale were discarded. The remaining hemispheres were then separated and homogenized in ice cold buffer containing trizma base (50 mmol/L), $\mathrm{NaCl}$ (150 mmol/L), EGTA (1 mmol/L), glycerol (10\%), triton (1\%) and $1 \%$ protease inhibitors cocktail. After centrifugation (20 min at $10,000 \mathrm{~g}$ at $\left.+4^{\circ} \mathrm{C}\right)$, supernatants were stored at $-80^{\circ} \mathrm{C}$ until measurement of proteins and BDNF levels whereas tissue pellets were kept for assessing the degree of embolization. BDNF levels were determined with a commercial sandwich ELISA kit (Chemikine, Chemicon International, USA) according to the manufacturer's instructions. Briefly, after dilution in the homogenization buffer $(1 / 10, v / v$, see above for its composition), $50 \mu \mathrm{l}$ of brain homogenates were incubated overnight in precoated microplates. They were then incubated with biotinylated anti-BDNF antibody followed by HRP-streptavidin. The oxidation of the enzyme substrate, the $3,3^{\prime}, 5,5^{\prime}$ tetramethylbenzidine (TMB), was measured at $450 \mathrm{~nm}$ using a plate reader (vector-3 1420 multilabe, Perkin Elmer, Waltham, USA). All assays were performed in triplicate. Hemispheric BDNF levels were expressed in $\mathrm{pg} / \mathrm{mg}$ of proteins.

\subsection{Assessment of the degree of embolization}


This determination was assessed by counting in the lesioned hemisphere the number of microspheres as previously described in details (Demougeot et al., 2001). The centrifugation pellets were dissolved in $5 \mathrm{ml}$ of $20 \% \mathrm{KOH}$ and centrifuged at $500 \mathrm{~g}$. The microspheres were then re-suspended in $0.5 \mathrm{ml} \mathrm{KOH}$ and the number present in the hemisphere was calculated by counting $50 \mu \mathrm{l}$ of the suspension in quadruplicate on a light microscope by two persons blinded to the experimental conditions.

\subsection{Cellular localization of BDNF}

Chloral-anaesthetized rats were transcardially perfused with saline and then with $4 \%$ paraformaldehyde in $0.1 \mathrm{M}$ phosphate buffer $(\mathrm{pH} 7.5)$. The removed brains were postfixed in the same fixative for $1 \mathrm{~h}$ and transferred $48 \mathrm{~h}$ in $20 \%$ sucrose solution in $0.4 \mathrm{M}$ phosphate buffer. They were frozen in isopentane at $-40^{\circ} \mathrm{C}$ and stored at $-80^{\circ} \mathrm{C}$. Multiple sections $(20$ $\mu \mathrm{m}$, starting $+1.7 \mathrm{~mm}$ to bregma and extending back to $-4.0 \mathrm{~mm}$ to bregma) were cut in a cryostat (HMSSO, Microm, Francheville, France) at $-20^{\circ} \mathrm{C}$ and collected on SuperFrost Plus slides. After rinsing in PBS ( $\mathrm{pH} 7.4)$, the sections were treated 10 min with proteinase $\mathrm{K}(10$ $\mu \mathrm{g} / \mathrm{ml}$ ) at room temperature (RT) for antigen retrieval and incubated for $2 \mathrm{~h}$ in PBS containing $10 \%$ goat serum (GS), $0.1 \%$ Triton $\mathrm{X}-100,0.2 \%$ Tween 20 in order to block the non-specific binding sites. Thereafter, the sections were incubated for $3 \mathrm{~d}$ at $4^{\circ} \mathrm{C}$ in the same medium containing the rabbit polyclonal antibody recognizing BDNF (dilution 1:100) in the presence of monoclonal antibodies recognizing either OX-42 (dilution 1:100), GFAP (dilution 1:500) or NeuN (dilution 1:500) in order to assess BDNF expression in microglia/macrophages, astrocytes and neurons, respectively. After three washes for $10 \mathrm{~min}$ in PBS, antibody visualization was achieved by the incubation for 3h (RT) with Alexa 488-conjugated antimouse and/or Alexa 568-conjugated anti-rabbit lgGs (1:1500). Negative controls were prepared by omitting the primary antibodies. The sections were then coverslipped with a fluorescent mounting containing $1.5 \mu \mathrm{g} / \mathrm{ml}$ DAPI (Vectashield Mouting Medium with DAPI, Vector Laboratories,USA) and observed with a confocal miscroscope (LEICA SP2, AOBS). BDNF expression in the different cerebral cells was graded on a scale from 0 to 3 ( 0 no 
expression; 1 mild expression; 2 moderate expression; 3 high expression) by two persons blinded to the experimental conditions.

\subsection{Measurement of GFAP expression}

Immunoblot analysis was performed on brain homogenates used for the measurement of BDNF levels. Equal amounts of total proteins (10 $\mu \mathrm{g} / \mathrm{lane})$ were dissolved in $62.5 \mathrm{mM}$ Tris$\mathrm{HCl}(\mathrm{pH} 6.8), 2 \%$ SDS, $10 \%$ glycerol, $0.01 \%$ bromophenol blue and were heated at $85^{\circ} \mathrm{C}$ for 10 min. Proteins were separated on $10 \%$ SDS-PAGE according to the method of Laemmli (1970). Proteins were electrophoretically transferred onto PVDF membrane (0.2 $\mu \mathrm{m}$ pore size) in cold transfer buffer [25 mM Tris- $\mathrm{HCl}(\mathrm{pH} 8.3), 192 \mathrm{mM}$ glycine, and 20\% methanol]. The blots were incubated overnight at $4^{\circ} \mathrm{C}$ in $5 \%$ non-fat dry milk in TBS buffer [20 mM Tris$\mathrm{HCl}(\mathrm{pH} 7.6)$ and $137 \mathrm{mM} \mathrm{NaCl}$ containing $0.1 \%$ Tween 20 to block unspecific binding. Membranes were washed, incubated for $4 \mathrm{~h}$ at RT with the monoclonal anti-GFAP antibody $(1 / 2000)$ and for 90 min with horseradish peroxidase-conjugated anti-mouse $\lg G(1 / 50000)$. The membranes were stripped and probed with a mouse monoclonal anti- $\beta$-actin antibody (1/5000; A-5441, Sigma) used as an internal control. Protein-antibody complexes were visualized using the enhanced chemiluminescence Western blotting detection system $\left(\mathrm{ECL}^{+}\right.$, GE Healthcare). The band densities were determined by scanning densitometry (GS-800, Bio-Rad Laboratories). Data were expressed as arbitrary units.

\subsection{Experimental groups}

The first set of experiments was designed for the assessment of the relationship between BDNF levels and neuronal death severity, and the the impact of embolization on hemispheric BDNF production. Rats $(n=74)$ were injected with 2000,3000 or 4000 microspheres in order to induce a large panel of stroke severities. Eleven rats died during the surgical procedure and additional rats $(n=23)$ died overnight. Surviving rats $(n=51)$ were euthanized $4 \mathrm{~h}, 24 \mathrm{~h}$, or $8 \mathrm{~d}$ after embolization. BDNF levels were measured in $4 \mathrm{~h}-, 24 \mathrm{~h}$ - and 8d-embolized rats (groups E 4h, E 24h, E 8d, respectively, $n=10$ for each group) selected 
from their degree of brain embolization in order to obtain a similar range of neuronal death severity (i.e. of degree of embolization) in the three groups of rats. As shown in figure 1, the repartition of rats according to their degree of embolization was not different between groups. The individual degree of embolization was plotted against the individual BDNF levels or GFAP expression. BDNF levels were also measured in intact rats $(n=7)$.

The second set of experiments was performed to assess the impact of stroke on BDNF cellular expression. Based on the results of the first experiment showing that all rats survived after a low degree of embolization, rats were injected with 2000 microspheres $(n=10)$. Then, the animals were euthanized $4 h(n=3), 24 h(n=3)$ or $8 d(n=4)$ after embolization. For this experiment, the degree of embolization cannot be determined since these brains were dedicated to the realization of brain sections. Cellular localization of BDNF was also studied in intact rats $(\mathrm{n}=5)$.

\subsection{Statistical analysis}

Hemispheric BDNF levels were expressed as mean \pm standard deviation of $n$ rats. The Kruskall-Wallis non parametric test was used to detect a global difference between groups. If the $\mathrm{P}$ value was below 0.05 , we performed pairwise comparison between pre-ischemic data and data collected at $4 \mathrm{~h}, 24 \mathrm{~h}$, or $8 \mathrm{~d}$ post-ischemia using the Mann-Whitney U-test and the Bonferroni's test as a post-hoc test. The comparison was significant if $P<0.016(0.05 / 3$ comparisons).

The Kendall rank correlation coefficient (tau) was applied to test the relationship between

BDNF levels and the degree of embolization, and between BDNF levels and GFAP expression. The relationship was considered significant if $P<0.05$. 


\section{Results}

\subsection{Relationship between the individual BDNF levels and degree of embolization}

The figure 2 shows the relationship between BDNF levels and the degree of embolization. For both hemispheres, no relationship was observed between the two parameters in groups E 4h (Fig. 2A) and E 24h (Fig. 2B). In contrast, a positive correlation was observed between BDNF levels of the lesioned hemisphere and the degree of embolization after $8 \mathrm{~d}$ of ischemia (group $\mathrm{E} 8 \mathrm{~d}$, tau $=0.556, \mathrm{p}=0.0187$, Fig. $2 \mathrm{C}$ ). Thus, the BDNF content of either the lesioned or the unlesioned hemisphere did not inversely correlate to neuronal death severity whatever the delay after stroke onset.

\subsection{Effect of ischemic stroke on BDNF immunoreactivity}

In embolized rats, lesions were confined to the hemisphere ipsilateral to the injection site of microspheres and primarily affected the parietotemporal cortex and the thalamostriate areas except in one rat of group E 8d in which the hippocampus was partly lesioned. Even though the infarction was unilateral, stroke-induced changes in BDNF-immunoreactivity (BDNF-IR) were found in both hemispheres. However, whereas BDNF-IR was restricted to neurons and ependymal cells in the contralateral hemisphere, it extended to endothelial cells and astromicroglia in the ipsilateral hemisphere. Because the cellular pattern of BDNF-IR was independent on the lesions localization, we choose to show micrographs from brain slices passing through a cortical lesion (Fig. 3-5), thus allowing visualization of BDNF-IR changes occurring at the pial surface. Unlike previous studies that reported a selective neuronal localization of BDNF in adult rat brain (Kawamoto et al., 1996; Schmidt-Kastner et al., 1996), neuronal BDNF expression (Fig. 3A) was also associated with BDNF staining of ependymal cells in intact rats. Not only ependymal cells of the pia (Fig. 3A) but also ependymal cells of the lateral ventricles and of the choroid plexus were BDNF positive (Fig. 3B). Noteworthy, BDNF expression in ependymal cells (without precision on their localization) was previously observed in human brain (Kerschensteiner et al., 1999), and low levels of BDNF mRNA was reported in choroid plexus in rats (Timmusk et al., 1995). 
After $4 \mathrm{~h}$ of ischemia, BDNF staining was increased in ependymocytes of the pia and neurons (Fig. 3C) localized either around (Fig. 3D) or inside the infarcts (Fig. 3E) as compared to intact rats. A mild BDNF staining was also detected in endothelial cells of arterioles located inside the lesions (not shown).

After $24 \mathrm{~h}$ of ischemia (Fig. 4), perilesional neurons and ependymocytes of the pia still exhibited strong BDNF-IR (Fig. 4A). Between 4h and 24h post-lesions, changes neither in the number of perilesional neurons positive for BDNF nor in their BDNF-IR intensity were observed. Importantly, neuronal loss in the lesions was near complete at $24 \mathrm{~h}$ of ischemia and no residual BDNF-stained neurons were observed within the infarcts at this time. In contrast, endothelial cells of arterioles confined to the lesions were strongly positive for BDNF (Fig. 4B). Although we didn't use specific endothelial marker, the pattern of BDNF staining as well as the size and morphology of nucleus of BDNF positive cells undoubtedly argue for BDNF expression by these cells. Moreover, please note that the cells immediately in contact with the microsphere show an intense BDNF staining (Fig. 4B, insert). In addition, a subset of round-shaped cells positive for the microglia/macrophages marker OX-42 showed BDNF staining. These cells were localized at the inner border of the lesions (Fig. 4CF).

After $8 d$ of ischemia, perilesional neurons still exhibited important BDNF-IR (Fig. 5A, B) as compared to intact rats. However, at this time, the neuronal staining was of lower intensity as compared to that observed after $4 \mathrm{~h}$ or $24 \mathrm{~h}$ of ischemia. BDNF-IR of ependymocytes of the pia was not different from baseline values (see Fig. 3A). Numerous cells positive for BDNF and GFAP were observed around the lesions, around vessels within the lesions and also at the cortical surface (Fig. $5 \mathrm{C}-\mathrm{F}$ ). Of note, the lesions were populated by OX-42 positive cells which were all BDNF negative (Fig. 5G-J).

In the contralateral hemisphere, BDNF staining was above control values in neurons and ependymal cells after $4 \mathrm{~h}$ and $24 \mathrm{~h}$ of ischemia only (data not shown). However, their staining 
was found less intense in comparison to the one observed for the corresponding cells in the lesioned hemisphere.

\subsection{Contribution of neuronal versus non neuronal cells in stroke induced BDNF production} In intact rats, hemispheric BDNF contents (pg/mg of proteins) were $33.30 \pm 4.88$ for the left hemisphere and $35.21 \pm 2.34$ for the right hemisphere. As shown in figure 6 , unilateral embolization increased BDNF production in both hemispheres. However, the effect was more severe and long-lasting in the lesioned hemisphere.

The time course of BDNF levels in the lesioned hemisphere reveals an increased production of this neurotrophin during the first $4 \mathrm{~h}$ of ischemia and the $4-24 \mathrm{~h}$ post-stroke interval. During the $24 \mathrm{~h}-8 \mathrm{~d}$ post-stroke period, BDNF production decreased but the BDNF content in the lesioned hemisphere was still above control values at $8 \mathrm{~d}$ of ischemia. These changes were compared to the pattern of BDNF cellular localization and expression intensity which are summarized in the Table 1.

At $4 \mathrm{~h}$ of ischemia, BDNF levels were $150 \%$ of baseline values. That BDNF production was associated with a marked increase in BDNF expression in neurons around or inside the lesions and in ependymal cells, and also with a mild BDNF expression in endothelial cells as compared to the expression observed in intact rats. Regarding the cellular distribution and intensity of BDNF staining, hemispheric BDNF production mainly originates from an increase in BDNF synthesis by neurons during the first $4 \mathrm{~h}$ of ischemia.

During the 4-24h post-stroke period, an additional and important rise in hemispheric BDNF content occurred in the lesioned hemisphere despite an aggravation of neuronal death. The BDNF levels (pg/mg of proteins) increased from $53.9 \pm 10.2$ at $4 \mathrm{~h}$ to $81.6 \pm 11.4$ at $24 \mathrm{~h}$. Between these two time points, variation in BDNF staining was neither observed in ependymal cells nor in surviving neurons located around infarctions. Therefore, the important BDNF hemispheric production observed within the $4 \mathrm{~h}-24 \mathrm{~h}$ post-stroke interval was attributable to OX-42-positive and endothelial cells, which both exhibited intense BDNF staining at $24 \mathrm{~h}$ but not at $4 \mathrm{~h}$ of ischemia. Noteworthy, we can assume that OX-42 staining at 
$24 \mathrm{~h}$ of ischemia was very likely due to local resident microglia since monocytes infiltration has been shown to not occur before $72 \mathrm{~h}$ after stroke (Engberink et al., 2008).

The post-stroke $24 \mathrm{~h}-8 \mathrm{~d}$ interval was characterized by an important fall in BDNF levels (from $81.6 \pm 11.4$ to $41.7 \pm 4.3, \mathrm{pg} / \mathrm{mg}$ of proteins) in the lesioned hemisphere, which however remained above baseline values at $8 \mathrm{~d}$ of ischemia. At this time and as compared to control values, the increase in the hemispheric BDNF content was associated with an increase in BDNF staining in neurons and a robust BDNF staining in activated astrocytes. Importantly, a positive association was observed between individual BDNF levels and GFAP expression (tau $=0.494, p=0.035$, Fig. $7 A$ ). Taken together, these data argue for astrocytes as a main source of BDNF in the delayed stage of stroke. In addition, a positive correlation was also obtained between BDNF expression and the degree of embolization (tau=0.944, $p<0.005$, Fig. 7B), confirming that astroglial activation correlates with neuronal death severity as already described (Nagai et al. 2010).

Lastly, stroke-induced BDNF production by the unlesioned hemisphere was modest as compared to the lesioned hemisphere and significant only during the first $24 \mathrm{~h}$ of stroke (Fig. 6). According to the pattern of BDNF cellular expression in this hemisphere, BDNF overproduction was attributable to neurons and ependymal cells since only these cells showed an elevated BDNF staining as compared to intact rats. 


\section{Discussion}

Using an ischemic stroke model that offers the unique opportunity to assess the relationship between cerebral BDNF production and neuronal death severity, our study provides evidence that both neurons and non neuronal cells contribute to increase BDNF production after stroke and that the implicated-non-neuronal-cells differ according to the delay after stroke onset.

Increases in BDNF levels have been reported in pieces of tissue collected at the infarct or peri-infarct level (Kokaia et al., 1998; Madinier et al., 2009; Sulejczak et al., 2007). However, as BDNF can be transported in the axon in both anterograde or retrograde direction (DiStefano et al., 1992; Reynolds et al., 2000; von Bartheld et al., 1996), changes in BDNF levels in a specific brain area does not necessarily mean changes in BDNF production in that area. For instance, BDNF proteins have been detected in the adult rodent striatum despite the absence of BDNF mRNA (von Bartheld et al., 1996). In our study, BDNF levels were separately measured in the two whole hemispheres. Therefore, changes in hemispheric BDNF levels obligatory sign changes in BDNF production. According to this experimental paradigm, our results show that unilateral ischemic stroke increases BDNF production in both hemispheres even though the effect was found more intense and long lasting in the lesioned hemisphere. Contralateral changes in BDNF synthesize have been poorly investigated after stroke as compared to ipsilateral changes. However, consistent with enhanced BDNF production in areas opposite to the lesion site, increased BDNF mRNA has been reported in the contralateral hippocampus after focal brain ischemia (Arai et al., 1996; Kokaia et al., 1995).

In situ hybridization studies in animal models of stroke have revealed that genes encoding BDNF are specifically induced in neurons (Comelli et al., 1992; Kokaia et al., 1995; Rickhag et al., 2007; Zhao et al., 2000), suggesting that neurons represent the unique source 
of BDNF after stroke. However, these studies focus on the very acute stage of stroke, and therefore miss the opportunity to detect BDNF mRNA in activated glial cells, which however have shown to express BDNF (Komitova et al., 2006; Madinier et al., 2009; Sato et al., 2009; Sulejczak et al., 2007). Our study provides evidence that both neurons and non neuronal cells produce substantial amount of BDNF after stroke, but that their relative contribution is dependent on the delay after stroke onset. In the first $4 \mathrm{~h}$ of stroke, our results show that increase in BDNF production is mainly due to upregulation of BDNF by neurons located inside and at vicinity of the lesions, thus confirming results of in situ hybridization studies. Later, the contribution of endothelial cells (microvessels within the lesion) and microglial cells (around lesions) becomes predominant, whereas in a more delayed stage of stroke, BDNF overproduction involves neurons again and astrocytes. To the best of our knowledge, our study is the first to report BDNF upregulation by endothelial cells in the ischemic brain. This result is important regarding the growing interest for the cross-talk between endothelial cells and other cells of the neurovascular unit in the pathophysiology of stroke (Arai et al., 2009). Another exciting new finding of the present study is that ependymal cells respond to an ischemic insult by BDNF upregulation even though their contribution in stroke-induced BDNF production seems to be modest. However, recent studies show that ependymal cell of the lateral ventricles can be activated to generate neuroblasts in the ischemic brain (Carlen et al., 2009). In addition, cellular therapy using ependymal cells could represent a new opportunity since it has been shown that animals transplanted with encapsulated choroid plexus displayed a reduction in both functional deficit and lesion size after stroke (Borlongan et al., 2004a).

Cerebral endogenous BDNF may exert multiple beneficial effects after an ischemic insult. For instance, BDNF has been identified as a neuroprotective agent (Schabitz et al., 1997; Wu, 2005), a promoter of angiogenesis (Kermani and Hempstead, 2007), neurogenesis (Keiner et al., 2009; Schabitz et al., 2007), and synaptic plasticity (Waterhouse and $\mathrm{Xu}, 2009)$. The present study, demonstrating the implication of non neuronal cells in 
stroke-induced BDNF neosynthesis, identifies these cells as potential targets of strategies aimed at improving recovery after stroke. In this context, decreases in perilesional BDNF levels by abrogation of early microglial activation reduces neuroplastic changes (Madinier et al., 2009), suggesting that a targeted protection of early activated microglial cells could represent an innovative option to potentiate post-stroke neuroregenerative responses. Similarly, the BDNF synthesis by endothelial cells may be also beneficial since BDNF produced by these cells may guide the migration of neuronal precursors toward the lesion (Snapyan et al., 2009) and has been proposed to be a trophic link between endothelium and neuronal survival (Guo et al., 2008). Lastly, in line with astrocytes as a cellular target of therapeutic interventions after stroke, there is increasing evidences showing that reactive astrocytes through the release of growth factors and related molecule have the potential to remodel neuronal circuitry in the damaged brain (Sofroniew and Vinters, 2010). Importantly, according to the relatively long delay for BDNF production by astrocytes after stroke, interventions targeting these cells offer the advantage to have a large therapeutic window.

The factors that control BDNF production by non neuronal cells after stroke are not well elucidated in vivo. However, evidences from in vitro studies using cells cultured in conditions mimicking ischemia reveal that these factors are multiple. For instance, astrocytes express BDNF when dopamine, glutamate or cytokines are added to the culture medium (Jean et al., 2008; Miklic et al., 2004; Saha et al., 2006). Human cerebral endothelial cells produce substantial amount of BDNF when exposed to pro-inflammatory conditions and to reduced oxygen avaibility (Bayas et al., 2002; Wang et al., 2006), and microglial cells respond to media from damaged neurons by BDNF upregulation (Lai and Todd, 2008). Lastly, choroids plexus produce BDNF when transplanted into the ischemic lesion (Borlongan et al., 2004b). Although not investigated directly here, our results suggest that the primarily signal involved in the control of BDNF production originates from ischemically injured neurons. Indeed, our results report similar individual BDNF levels after $4 \mathrm{~h}$ or $24 \mathrm{~h}$ of ischemia despite large difference in degree of embolization between rats. More convincing, 
the degree of embolization and BDNF levels were positively correlated at $8 \mathrm{~d}$ of ischemia. These data support the idea that higher is the stroke severity in term of neuronal death, the more important is the BDNF production by non neuronal cells. Assuming that BDNF upregulation represents a compensatory mechanism coping with neuronal death, interventions aimed at decreasing neuronal death (neuroprotection) might therefore be not as beneficial as expected because such strategies might decrease BDNF production by non neuronal cells. Although provocative, this idea is in concordance with the plethora of negative clinical trails with neuroprotective drugs in stroke patients (O'Collins et al., 2006). The possibility that non neuronal cells can compensate for neuronal death may also explain why an extensive brain lesion may be associated with less functional deficit than a small lesion (Irle, 1987) and why motor skill performance with the limb ipsilateral to the ischemic lesion is better in rats with larger lesion size (Allred and Jones, 2004).

In conclusion, our results suggest that more attention should be given to ependymal, endothelial cells, microglia and astrocytes in the design of strategies aimed at improving stroke recovery through BDNF-related mechanisms. Elaboration of such therapeutic options requires a better understanding of the in vivo mechanisms controlling extra-neuronal BDNF upregulation after ischemic stroke. 
Figure legends

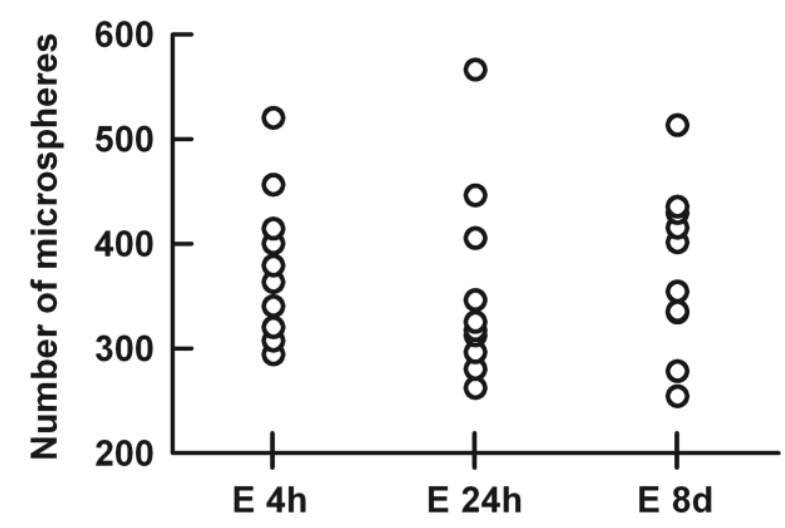

Fig. 1. Individual degree of embolization in $4 \mathrm{~h}-, 24 \mathrm{~h}-$ and $8 \mathrm{~d}$ embolized rats.

The microspheres were counted in the left hemispheres after injection of 2000, 3000 or 4000 microspheres into the left common carotid artery after ligature of the external carotid artery. Each dot represents one rat (10 rats per group). 

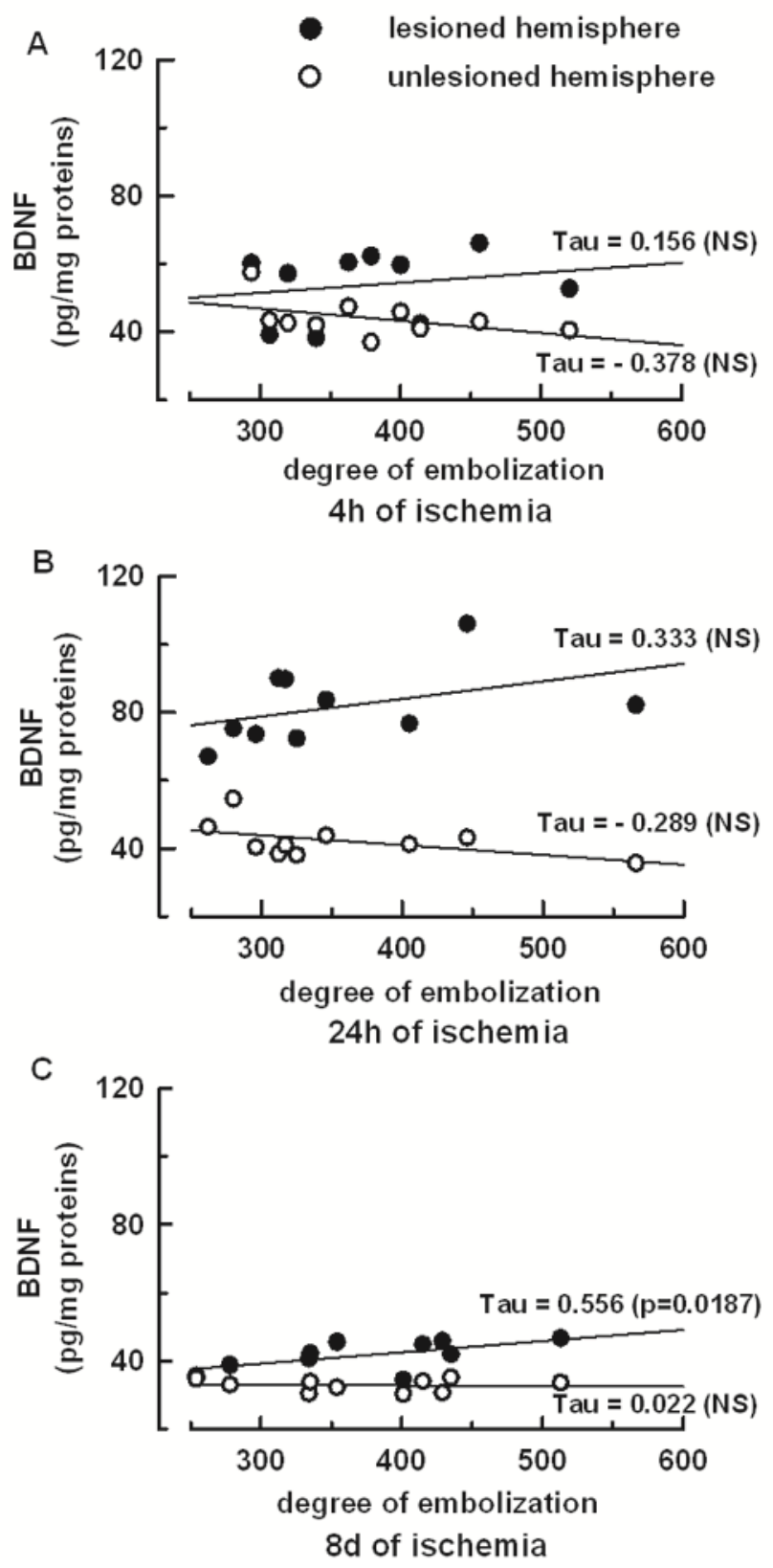

Fig. 2. Relationship between the hemispheric BDNF content and the degree of embolization.

The association was assessed in $4 \mathrm{~h}-(A), 24 \mathrm{~h}-(B)$ or $8 \mathrm{~d}-(\mathrm{C})$ embolized rats. Each dot represents a rat in which BDNF levels were separately measured in the lesioned (black dot) and the unlesioned (empty dots) hemispheres. 

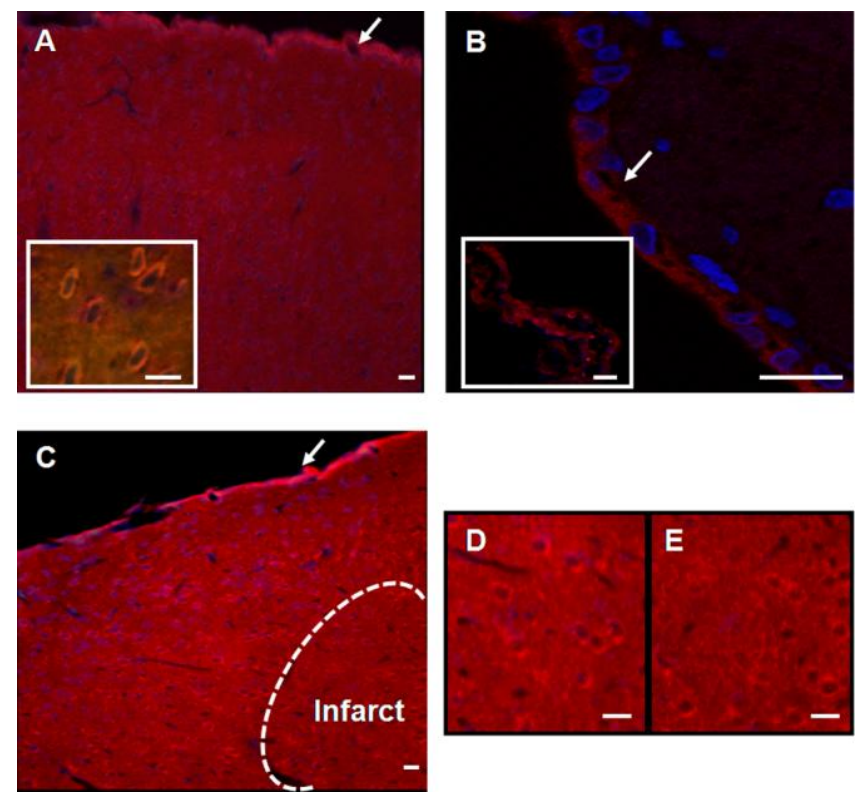

Fig. 3. Representative micrographs of BDNF staining in the presence of DAPI nuclear labeling in intact (A, B) and $4 \mathrm{~h}$-embolized rat (C, D, E).

(A) Moderate BDNF staining of neurons (the cells are NeuN positive as shown in the insert) and of ependymal cells of the pial surface (arrow) in intact rat, (B) ependymal cells of the ventricle wall (arrow) and of choroids plexus (insert) are BDNF positive in intact rat, (C) ependymal cells (arrow) as well as neurons exhibit intense BDNF staining at $4 \mathrm{~h}$ postembolization as compared to intact rat, (D) higher magnification of BDNF staining of neurons around the lesion, (E) higher magnification of BDNF staining of neurons localized inside the lesion. Scale bars $=20 \mu \mathrm{m}$. 

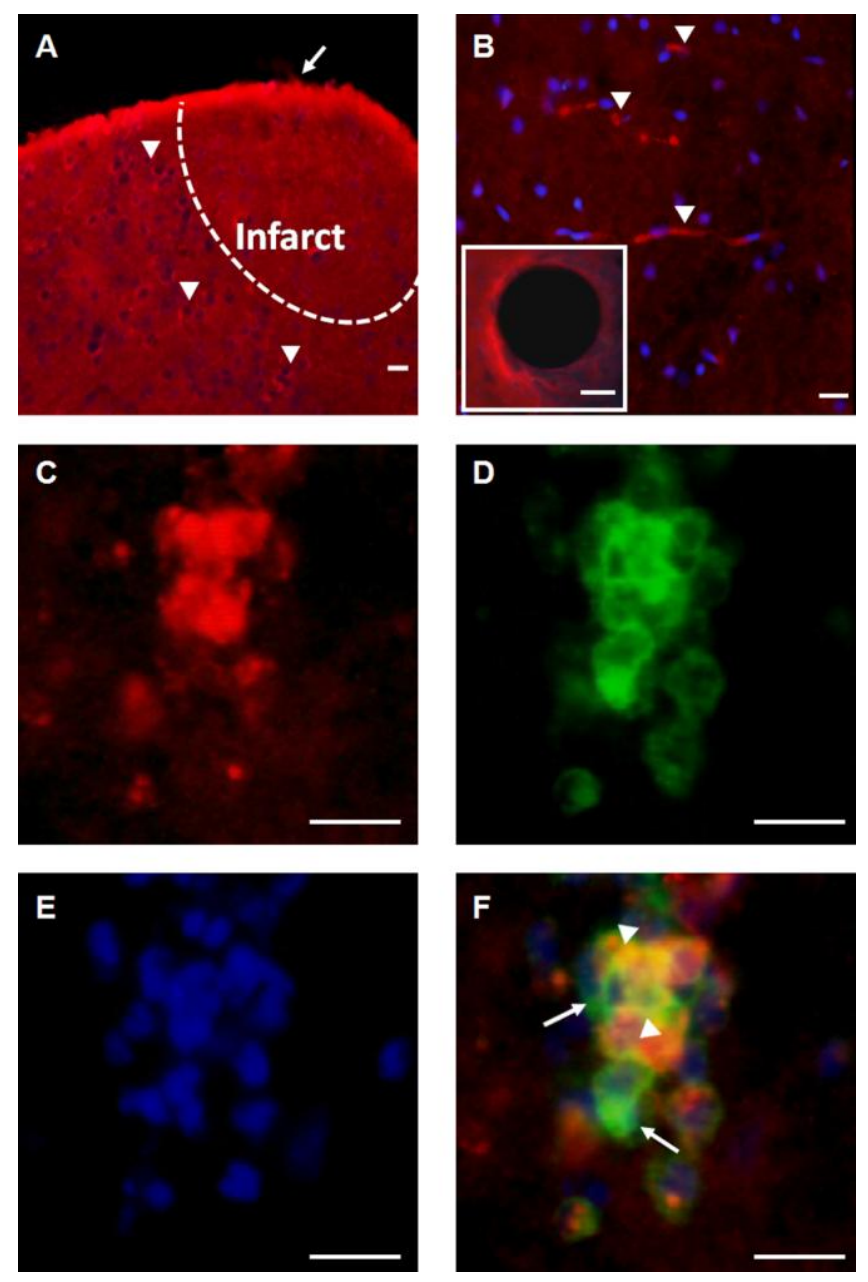

Fig. 4. Representative micrographs of BDNF staining in 24h-embolized rats (A-F).

(A) BDNF staining shows that ependymal cells of the pial surface (arrow) and neurons around the lesion (arrowheads) express BDNF. (B) BDNF staining in the presence of DAPI nuclear labeling shows that microvessels inside the lesion (arrowheads) are strongly positive for BDNF; higher magnification of a microsphere occluding an arteriole reveals an intense BDNF staining of endothelial cells (insert). (C-F) Representative micrographs of the inner border of the lesion from four identical sections. (C) Round-shaped BDNF-immunolabeled cells, (D) these cells are positive for OX-42, (E), DAPI nuclear labeling, (F) overlay of the three fluorochromes (Alexa Fluor 488, Alexa fluor 568 and DAPI) shows that certain (arrowheads) but not all (arrows) microglial cells (OX-42 positive cells) express BDNF. Scale bars $=20 \mu \mathrm{m}$. 

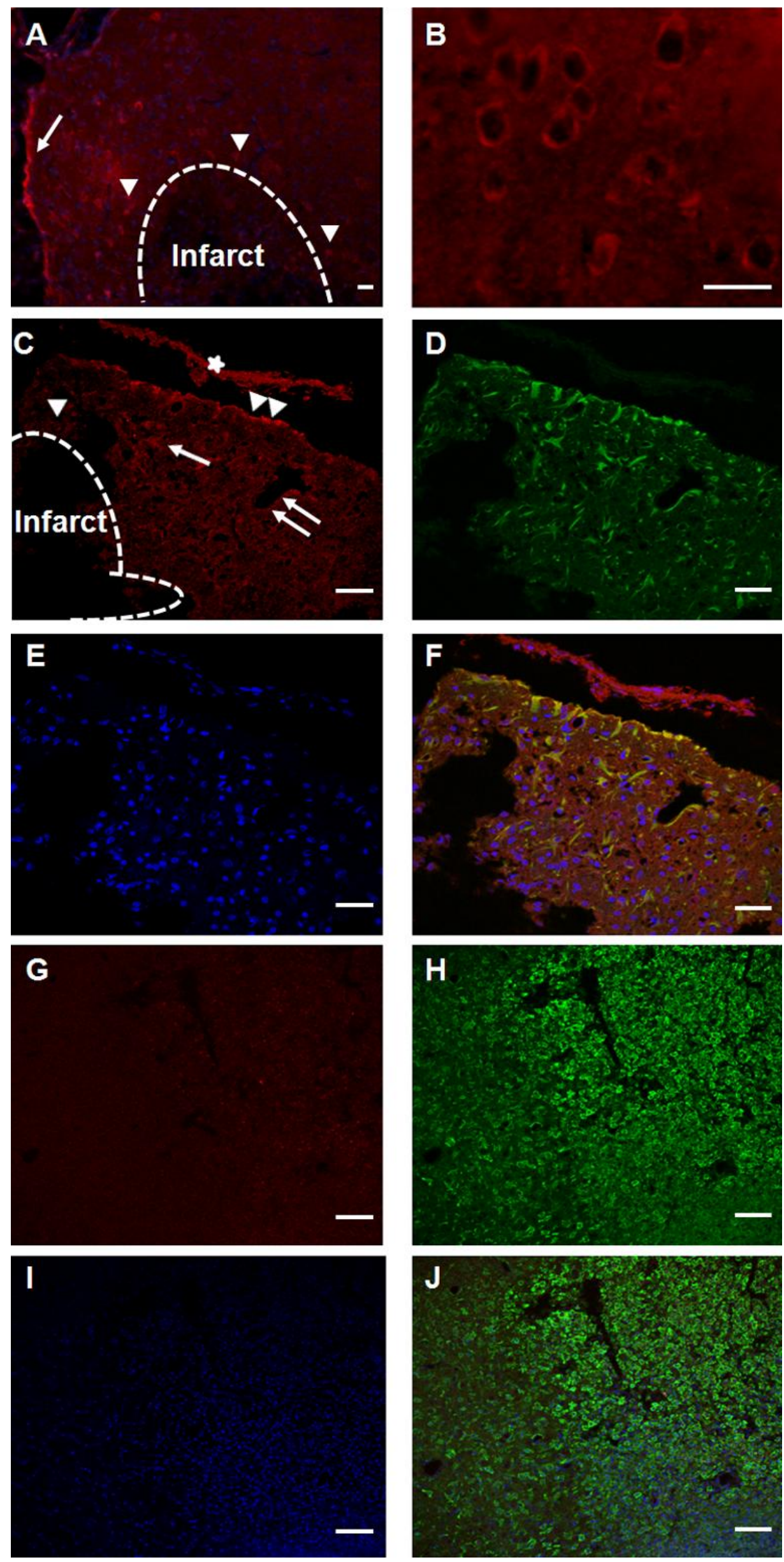


\section{Fig. 5. Representative micrographs of BDNF staining in 8d-embolized rats (A-J).}

(A) BDNF staining in the presence of DAPI nuclear labeling of ependymal cells of the pia (arrow) and of neurons localized around the lesion (arrowheads). Note the absence of BDNF positive cells inside the lesion, (B) higher magnification of BDNF-labeled neurons localized around the lesion, (C-F) Representative micrographs of the area surrounding the lesion from four identical brain sections, C) BDNF staining of the pia (asterisk) and numerous cells localized in the parenchyma (among them, cells localized at the cortical surface (double arrowheads), around the lesion with (arrow) or without (arrowhead) stellate shape and close to the vessels (double arrows), D) most of these cells are GFAP positive, E) DAPI nuclear labelling, F) overlay of the three fluorochromes (Alexa Fluor 488, Alexa fluor 568 and DAPI) shows that astrocytes (GFAP positive cells) are positive for BDNF whatever their localization, (G-J). Representative micrographs of the lesion from four identical brain sections, G) lack of BDNF staining inside the lesion, $H$ ) the lesion is invaded by OX-42 labeled cells, I) DAPI nuclear labelling, J) overlay of the three fluorochromes (Alexa Fluor 488, Alexa fluor 568 and DAPI) shows that microglial cells (OX-42 positive cells) do not express BDNF. Scale bar $=20$ $\mu \mathrm{m}$.

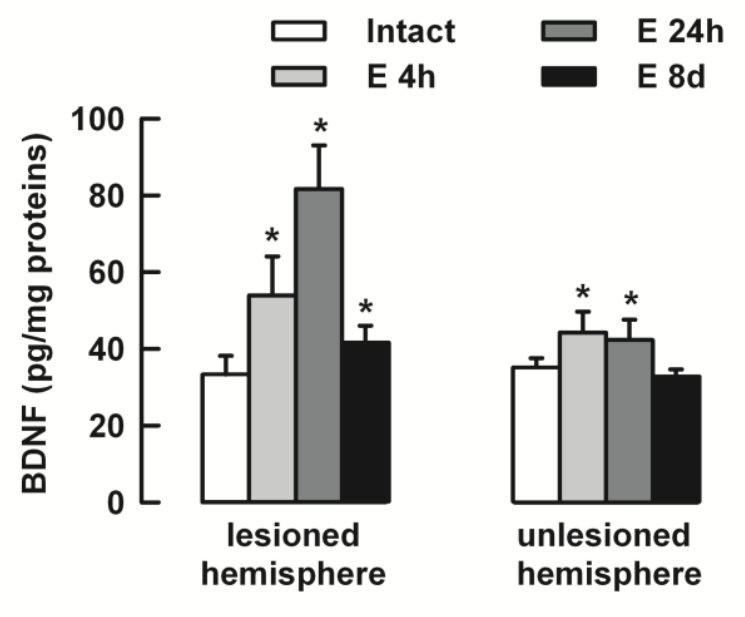

Fig. 6. Effect of stroke on BDNF production.

BDNF levels were measured by ELISA in the whole hemispheres of intact rats $(n=7)$ and $4 h-$, $24 h-$, and $8 d-$ embolized rats $(n=10$ for each group), * different from intact rats $(p<0.016)$. 

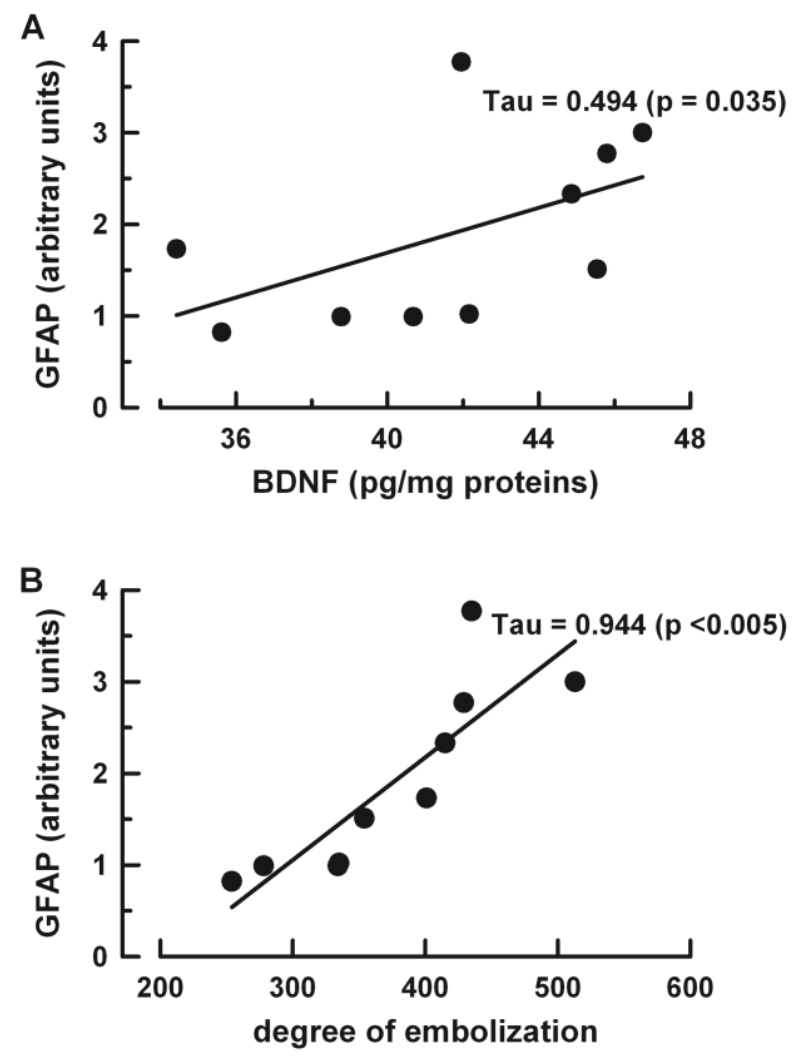

Fig. 7. Relationship between GFAP expression and the hemispheric BDNF content or the degree of embolization.

(A) Association between the GFAP expression and the BDNF content or (B) the degree of embolization. The measurements were performed in the embolized hemisphere of $8 d-$ embolized rats $(n=10)$. Each dot represents a rat.

\section{Acknowledgments:}

We thank Dr Christine Arnould for her technical assistance at the microscopy center, INRA, Dijon. This work was financially supported by Burgundy and the Faculty of Medicine of Dijon. 
Table 1:

Cellular BDNF localization in the lesioned hemisphere.

\begin{tabular}{|c|c|c|c|c|}
\hline & \multicolumn{4}{|c|}{ BDNF staining } \\
\hline & \multirow{2}{*}{$\begin{array}{c}\text { before } \\
\text { stroke } \\
(n=5)\end{array}$} & \multicolumn{3}{|c|}{ after stroke } \\
\hline & & $\begin{array}{c}4 \mathrm{~h} \\
(\mathrm{n}=3)\end{array}$ & $\begin{array}{l}24 \mathrm{~h} \\
(\mathrm{n}=3)\end{array}$ & $\begin{array}{c}8 d \\
(n=4)\end{array}$ \\
\hline neurons & + & & & \\
\hline around lesion & & +++ & +++ & ++ \\
\hline within lesion & & ++ & 0 & 0 \\
\hline ependymal cells & + & ++ & ++ & + \\
\hline endothelial cells & - & + & +++ & - \\
\hline microglial cells & - & - & +++ & - \\
\hline astrocytes & - & - & - & +++ \\
\hline
\end{tabular}




\section{References}

Allred, R.P., Jones, T.A., 2004. Unilateral ischemic sensorimotor cortical damage in female rats: forelimb behavioral effects and dendritic structural plasticity in the contralateral homotopic cortex. Exp Neurol 190, 433-445.

Arai, K., Jin, G., Navaratna, D., Lo, E.H., 2009. Brain angiogenesis in developmental and pathological processes: neurovascular injury and angiogenic recovery after stroke. Febs J 276, 4644-4652.

Arai, S., Kinouchi, H., Akabane, A., Owada, Y., Kamii, H., Kawase, M., Yoshimoto, T., 1996. Induction of brain-derived neurotrophic factor (BDNF) and the receptor trk B mRNA following middle cerebral artery occlusion in rat. Neurosci Lett 211, 57-60.

Batchelor, P.E., Liberatore, G.T., Wong, J.Y., Porritt, M.J., Frerichs, F., Donnan, G.A., Howells, D.W., 1999. Activated macrophages and microglia induce dopaminergic sprouting in the injured striatum and express brain-derived neurotrophic factor and glial cell line-derived neurotrophic factor. J Neurosci 19, 1708-1716.

Bayas, A., Hummel, V., Kallmann, B.A., Karch, C., Toyka, K.V., Rieckmann, P., 2002. Human cerebral endothelial cells are a potential source for bioactive BDNF. Cytokine 19, 55-58.

Borlongan, C.V., Skinner, S.J., Geaney, M., Vasconcellos, A.V., Elliott, R.B., Emerich, D.F., 2004a. CNS grafts of rat choroid plexus protect against cerebral ischemia in adult rats. Neuroreport 15, 1543-1547.

Borlongan, C.V., Skinner, S.J., Geaney, M., Vasconcellos, A.V., Elliott, R.B., Emerich, D.F., 2004b. Intracerebral transplantation of porcine choroid plexus provides structural and functional neuroprotection in a rodent model of stroke. Stroke 35, 2206-2210.

Bralet, A.M., Beley, A., Beley, P., Bralet, J., 1979. Brain edema and blood-brain barrier permeability following quantitative cerebral microembolism. Stroke 10, 34-38.

Carlen, M., Meletis, K., Goritz, C., Darsalia, V., Evergren, E., Tanigaki, K., Amendola, M., Barnabe-Heider, F., Yeung, M.S., Naldini, L., Honjo, T., Kokaia, Z., Shupliakov, O., Cassidy, R.M., Lindvall, O., Frisen, J., 2009. Forebrain ependymal cells are Notchdependent and generate neuroblasts and astrocytes after stroke. Nat Neurosci 12, 259-267.

Chen, J., Zacharek, A., Zhang, C., Jiang, H., Li, Y., Roberts, C., Lu, M., Kapke, A., Chopp, M., 2005a. Endothelial nitric oxide synthase regulates brain-derived neurotrophic factor expression and neurogenesis after stroke in mice. J Neurosci 25, 2366-2375.

Chen, J., Zhang, C., Jiang, H., Li, Y., Zhang, L., Robin, A., Katakowski, M., Lu, M., Chopp, M., 2005b. Atorvastatin induction of VEGF and BDNF promotes brain plasticity after stroke in mice. J Cereb Blood Flow Metab 25, 281-290.

Cohen-Cory, S., Kidane, A.H., Shirkey, N.J., Marshak, S., 2010. Brain-derived neurotrophic factor and the development of structural neuronal connectivity. Dev Neurobiol 70, 271-288. 
Comelli, M.C., Seren, M.S., Guidolin, D., Manev, R.M., Favaron, M., Rimland, J.M., Canella, R., Negro, A., Manev, H., 1992. Photochemical stroke and brain-derived neurotrophic factor (BDNF) mRNA expression. Neuroreport 3, 473-476.

Cowansage, K.K., LeDoux, J.E., Monfils, M.H., 2010. Brain-derived neurotrophic factor: a dynamic gatekeeper of neural plasticity. Curr Mol Pharmacol 3, 12-29.

Demougeot, C., Garnier, P., Mossiat, C., Bertrand, N., Giroud, M., Beley, A., Marie, C., 2001. $\mathrm{N}$-Acetylaspartate, a marker of both cellular dysfunction and neuronal loss: its relevance to studies of acute brain injury. J Neurochem 77, 408-415.

DiStefano, P.S., Friedman, B., Radziejewski, C., Alexander, C., Boland, P., Schick, C.M., Lindsay, R.M., Wiegand, S.J., 1992. The neurotrophins BDNF, NT-3, and NGF display distinct patterns of retrograde axonal transport in peripheral and central neurons. Neuron 8, 983-993.

Engberink, R.D., Blezer, E.L., Hoff, E.I., van der Pol, S.M., van der Toorn, A., Dijkhuizen, R.M., de Vries, H.E., 2008. MRI of monocyte infiltration in an animal model of neuroinflammation using SPIO-labeled monocytes or free USPIO. J Cereb Blood Flow Metab 28, 841-851.

Greenberg, M.E., Xu, B., Lu, B., Hempstead, B.L., 2009. New insights in the biology of BDNF synthesis and release: implications in CNS function. J Neurosci 29, 12764-12767.

Guo, S., Kim, W.J., Lok, J., Lee, S.R., Besancon, E., Luo, B.H., Stins, M.F., Wang, X., Dedhar, S., Lo, E.H., 2008. Neuroprotection via matrix-trophic coupling between cerebral endothelial cells and neurons. Proc Natl Acad Sci U S A 105, 7582-7587.

Irle, E., 1987. Lesion size and recovery of function: some new perspectives. Brain Res 434, 307-320.

Jean, Y.Y., Lercher, L.D., Dreyfus, C.F., 2008. Glutamate elicits release of BDNF from basal forebrain astrocytes in a process dependent on metabotropic receptors and the PLC pathway. Neuron Glia Biol 4, 35-42.

Kawamoto, Y., Nakamura, S., Nakano, S., Oka, N., Akiguchi, I., Kimura, J., 1996. Immunohistochemical localization of brain-derived neurotrophic factor in adult rat brain. Neuroscience 74, 1209-1226.

Keiner, S., Witte, O.W., Redecker, C., 2009. Immunocytochemical detection of newly generated neurons in the perilesional area of cortical infarcts after intraventricular application of brain-derived neurotrophic factor. J Neuropathol Exp Neurol 68, 83-93.

Kermani, P., Hempstead, B., 2007. Brain-derived neurotrophic factor: a newly described mediator of angiogenesis. Trends Cardiovasc Med 17, 140-143.

Kerschensteiner, M., Gallmeier, E., Behrens, L., Leal, V.V., Misgeld, T., Klinkert, W.E., Kolbeck, R., Hoppe, E., Oropeza-Wekerle, R.L., Bartke, I., Stadelmann, C., Lassmann, H., Wekerle, H., Hohlfeld, R., 1999. Activated human T cells, B cells, and monocytes produce brain-derived neurotrophic factor in vitro and in inflammatory brain lesions: a neuroprotective role of inflammation? J Exp Med 189, 865-870.

Kim, M.W., Bang, M.S., Han, T.R., Ko, Y.J., Yoon, B.W., Kim, J.H., Kang, L.M., Lee, K.M., Kim, M.H., 2005. Exercise increased BDNF and trkB in the contralateral hemisphere of the ischemic rat brain. Brain Res 1052, 16-21. 
Kokaia, Z., Andsberg, G., Yan, Q., Lindvall, O., 1998. Rapid alterations of BDNF protein levels in the rat brain after focal ischemia: evidence for increased synthesis and anterograde axonal transport. Exp Neurol 154, 289-301.

Kokaia, Z., Zhao, Q., Kokaia, M., Elmer, E., Metsis, M., Smith, M.L., Siesjo, B.K., Lindvall, O., 1995. Regulation of brain-derived neurotrophic factor gene expression after transient middle cerebral artery occlusion with and without brain damage. Exp Neurol 136, 7388.

Komitova, M., Perfilieva, E., Mattsson, B., Eriksson, P.S., Johansson, B.B., 2006. Enriched environment after focal cortical ischemia enhances the generation of astroglia and NG2 positive polydendrocytes in adult rat neocortex. Exp Neurol 199, 113-121.

Laemmli, U.K., 1970. Cleavage of structural proteins during the assembly of the head of bacteriophage T4. Nature 227, 680-685.

Lai, A.Y., Todd, K.G., 2008. Differential regulation of trophic and proinflammatory microglial effectors is dependent on severity of neuronal injury. Glia 56, 259-270.

Lipsky, R.H., Marini, A.M., 2007. Brain-derived neurotrophic factor in neuronal survival and behavior-related plasticity. Ann N Y Acad Sci 1122, 130-143.

Madinier, A., Bertrand, N., Mossiat, C., Prigent-Tessier, A., Beley, A., Marie, C., Garnier, P., 2009. Microglial involvement in neuroplastic changes following focal brain ischemia in rats. PLoS One 4, e8101.

Mattson, M.P., 2008. Glutamate and neurotrophic factors in neuronal plasticity and disease. Ann N Y Acad Sci 1144, 97-112.

Miklic, S., Juric, D.M., Carman-Krzan, M., 2004. Differences in the regulation of BDNF and NGF synthesis in cultured neonatal rat astrocytes. Int J Dev Neurosci 22, 119-130.

Nagai, N., Kawao, N., Okada, K., Ishida, C., Okumoto, K., Ueshima, S., Suzuki, Y., Umemura, K., Matsuo, O., 2010. Initial brain lesion size affects the extent of subsequent pathophysiological responses. Brain Res 1322, 109-117.

Nagamoto-Combs, K., McNeal, D.W., Morecraft, R.J., Combs, C.K., 2007. Prolonged microgliosis in the rhesus monkey central nervous system after traumatic brain injury. J Neurotrauma 24, 1719-1742.

Nagappan, G., Lu, B., 2005. Activity-dependent modulation of the BDNF receptor TrkB: mechanisms and implications. Trends Neurosci 28, 464-471.

O'Collins, V.E., Macleod, M.R., Donnan, G.A., Horky, L.L., van der Worp, B.H., Howells, D.W., 2006. 1,026 experimental treatments in acute stroke. Ann Neurol 59, 467-477.

Ploughman, M., Windle, V., MacLellan, C.L., White, N., Dore, J.J., Corbett, D., 2009. Brainderived neurotrophic factor contributes to recovery of skilled reaching after focal ischemia in rats. Stroke 40, 1490-1495.

Reynolds, A.J., Bartlett, S.E., Hendry, I.A., 2000. Molecular mechanisms regulating the retrograde axonal transport of neurotrophins. Brain Res Brain Res Rev 33, 169-178. 
Rickhag, M., Teilum, M., Wieloch, T., 2007. Rapid and long-term induction of effector immediate early genes (BDNF, Neuritin and Arc) in peri-infarct cortex and dentate gyrus after ischemic injury in rat brain. Brain Res 1151, 203-210.

Saha, R.N., Liu, X., Pahan, K., 2006. Up-regulation of BDNF in astrocytes by TNF-alpha: a case for the neuroprotective role of cytokine. J Neuroimmune Pharmacol 1, 212-222.

Sato, Y., Chin, Y., Kato, T., Tanaka, Y., Tozuka, Y., Mase, M., Ageyama, N., Ono, F., Terao, K., Yoshikawa, Y., Hisatsune, T., 2009. White matter activated glial cells produce BDNF in a stroke model of monkeys. Neurosci Res 65, 71-78.

Schabitz, W.R., Schwab, S., Spranger, M., Hacke, W., 1997. Intraventricular brain-derived neurotrophic factor reduces infarct size after focal cerebral ischemia in rats. J Cereb Blood Flow Metab 17, 500-506.

Schabitz, W.R., Steigleder, T., Cooper-Kuhn, C.M., Schwab, S., Sommer, C., Schneider, A., Kuhn, H.G., 2007. Intravenous brain-derived neurotrophic factor enhances poststroke sensorimotor recovery and stimulates neurogenesis. Stroke 38, 2165-2172.

Schmidt-Kastner, R., Humpel, C., Wetmore, C., Olson, L., 1996. Cellular hybridization for BDNF, trkB, and NGF mRNAs and BDNF-immunoreactivity in rat forebrain after pilocarpine-induced status epilepticus. Exp Brain Res 107, 331-347.

Snapyan, M., Lemasson, M., Brill, M.S., Blais, M., Massouh, M., Ninkovic, J., Gravel, C., Berthod, F., Gotz, M., Barker, P.A., Parent, A., Saghatelyan, A., 2009. Vasculature guides migrating neuronal precursors in the adult mammalian forebrain via brainderived neurotrophic factor signaling. J Neurosci 29, 4172-4188.

Sofroniew, M.V., Vinters, H.V., 2010. Astrocytes: biology and pathology. Acta Neuropathol 119, 7-35.

Sulejczak, D., Ziemlinska, E., Czarkowska-Bauch, J., Nosecka, E., Strzalkowski, R., Skup, M., 2007. Focal photothrombotic lesion of the rat motor cortex increases BDNF levels in motor-sensory cortical areas not accompanied by recovery of forelimb motor skills. J Neurotrauma 24, 1362-1377.

Timmusk, T., Mudo, G., Metsis, M., Belluardo, N., 1995. Expression of mRNAs for neurotrophins and their receptors in the rat choroid plexus and dura mater. Neuroreport 6, 1997-2000.

Uchida, H., Yokoyama, H., Kimoto, H., Kato, H., Araki, T., 2010. Long-term changes in the ipsilateral substantia nigra after transient focal cerebral ischaemia in rats. Int $\mathrm{J}$ Exp Pathol 91, 256-266.

Vaynman, S., Ying, Z., Gomez-Pinilla, F., 2004. Hippocampal BDNF mediates the efficacy of exercise on synaptic plasticity and cognition. Eur J Neurosci 20, 2580-2590.

von Bartheld, C.S., Byers, M.R., Williams, R., Bothwell, M., 1996. Anterograde transport of neurotrophins and axodendritic transfer in the developing visual system. Nature 379 , 830-833.

Wang, H., Ward, N., Boswell, M., Katz, D.M., 2006. Secretion of brain-derived neurotrophic factor from brain microvascular endothelial cells. Eur J Neurosci 23, 1665-1670. 
Waterhouse, E.G., Xu, B., 2009. New insights into the role of brain-derived neurotrophic factor in synaptic plasticity. Mol Cell Neurosci 42, 81-89.

Wu, D., 2005. Neuroprotection in experimental stroke with targeted neurotrophins. NeuroRx 2, $120-128$.

Zhao, L.R., Mattsson, B., Johansson, B.B., 2000. Environmental influence on brain-derived neurotrophic factor messenger RNA expression after middle cerebral artery occlusion in spontaneously hypertensive rats. Neuroscience 97, 177-184. 